\title{
UTILIZATION OF PRE-AERATED SLUDGE IN ACTIVATED SLUDGE PROCESS
}

\author{
Sagar Gawande ${ }^{1}$, Archana V. Kelkar ${ }^{2}$ \\ ${ }^{1}$ Guide, Civil Department, Anantrao Pawar College of Engineering and Research ,/Savitribai Phule Pune University, \\ India \\ ${ }^{2}$ Student, Civil Department, Anantrao Pawar College of Engineering and Research, ,Savitribai Phule Pune University, \\ India
}

\begin{abstract}
The research was carried out with Pre aerated Sludge in Activated Sludge Process to observe the effect of Pre-aerated Sludge on BOD, COD , Phosphate, Nitrate, MLVSS mainly in treatment of dairy wastewater. The experimental process involves the conventional Activated Sludge Process (ASP) in which microorganisms are kept in suspension by mixing and aerating the wastewater. The study is to be conducted by following two methods: 1) utilizing non pre-aerated sludge and 2) utilizing preaerated sludge. In the first method the dairy wastewater measuring five liters and $400 \mathrm{ml}$ of non-pre-aerated sludge is filled in the aeration tank and was aerated in the aeration tank where air (or oxygen) was supplied for regular intervals of 30, 60, 90, 120 minutes respectively and samples are collected before aeration and at regular intervals. In the second method the dairy wastewater measuring five liters and $400 \mathrm{ml}$ of pre aerated sludge (with 20,40 and 60 minutes pre-aeration) are filled in aeration tank. This tank is aerated for regular intervals of 30, 60, 90, 120 minutes respectively. The samples are collected before aeration and at regular time intervals. The sludge is to be not recycled to the aeration tank. Testing of different parameters like BOD, COD, Phosphate, Nitrate and Mixed liquor volatile suspended solids was carried out on the samples aerated with different aeration time, with and without pre-aerated sludge and consequent results are to be found. By utilization of pre-aerated sludge, the concentrations of various parameters to be considered for study are to be found decreased when compared with the values of concentration without using pre-aerated sludge. It will be very clear that removal of various parameters from wastewater is effective up to the optimum period for pre-aeration beyond this period removal of various parameters from wastewater will not be effective.
\end{abstract}

Keywords: Activated Sludge Process, BOD, COD, Phosphate, Nitrate, MLVSS.

\section{INTRODUCTION}

An activated sludge process (ASP) is a most versatile biological process available to the designer for the treatment of almost any type of wastewater. Aerobic biological treatment basically involves stabilization of biodegradable organic content of wastewater by the mixed population of microorganisms. The process that essentially requires the presence of molecular oxygen for metabolic activity of microorganisms is called an aerobic process. The process can be designed to supply required oxygen either naturally (as in a trickling filter, aerobic stabilization ponds) or by artificial /mechanical means (as in activated sludge process, aerated lagoons) in the reactor. The process normally fails in the absence of oxygen.

In aerobic biological treatment basically involves stabilization of biodegradable organic content of wastewater by the mixed population of microorganisms. In simplest term during the stabilization of organic content, biodegradable organic matter is oxidized or synthesized by microorganisms in aerobic conditions to produce new cells, inert solids and other simple end products.

During the stabilization of organic content of wastewater, new cells (microorganisms) are also synthesized or produced. These generated new cells themselves are mainly organic in their composition and therefore increase BOD load on the system both as living cells and on their death by contributing as organic matter to wastewater.

Thus, on other hand we take help of a variety of microorganisms to remove the organic matter from wastewater during biological treatment and on the other hand, during treatment, we add organic solids to the wastewater in the form of new cells (also known as surplus microorganisms or surplus sludge). Such conditions therefore, demand the maintenance of proper balance of biomass in wastewater during the treatment. This is usually accomplished by controlling the growth of new cells in the biological system. For effective growth control and proper balance of biomass in the system, it is essential to have a clear concept or understanding about the kinetics of

- Microbial growth rate

- Substrate (organic matter or food) utilization rate

- Limiting substrate or nutrients that affect the growth of cells

- Endogenous decay or death rate of microorganisms in the system. 
- The proportionality constants obtained from kinetic equations derived for the above rates are called biokinetic coefficients or growth constants.

The bio-kinetic constants depend on the type of microbial species and environmental conditions like $\mathrm{pH}$, temperature; DO concentration, nutrients, inhibitory substances and degradability of organic substrate, etc. in wastewater. The treatment of wastewater, in general, means the partial reduction or complete removal of excessive impurities in the wastewater. The excessive impurities imply to the constituents concentrations that is more than the acceptable levels for final disposal or suitable reuse and recycling of treated wastewater.

\subsection{Objectives of the Research}

The objectives of the research are:-

a) To study the concentration of various parameters such as BOD, COD, Phosphate, Nitrate, Mixed liquor volatile suspended solids in the dairy wastewater.

b) To compare the removal efficiency of parameters of the effluent after treatment in conventional activated sludge process by using non pre-aerated sludge and by using preaerated sludge.

c) To find out the optimum duration for pre-aeration for efficient removal of these contaminants.

d) To develop inter-relationship between various parameters by regression analysis.

\subsection{Limitations of the Study}

The limitations of the study are:-

a) By utilization of pre-aerated sludge in conventional activated sludge process the parameters of the effluent can be removed effectively up to optimum duration of preaeration.

b) Beyond this optimum duration if sludge is aerated the efficiency of removal of these parameters decreases.

c) The efficiency of removal of pollutants depends upon various other parameters like temperature, dissolved oxygen concentration, nutrients, inhibitory substances and degradability of organic substrate, etc. in wastewater.

\section{MATERIALS AND METHODOLOGY}

\subsection{Preparation of Sludge}

For this experimental study we prepared the sludge. For culture development in aeration basin following procedure is adopted.

1. Take fresh dairy/domestic waste water or sludge from similar ETP in aeration tank (1-2\% of tank volume)

2. Fill remaining tank with fresh water

3. Check aerator blade immersion in the tank in case of surface aeration

4. Start aerator/Blowers

5. Aerate for a week. Check developed organisms microscopically.

6. Observe formation of biological flocks.
7. Add nutrients like Urea, Superphosphate if required to maintain BOD:N:P ratio as 100:5:1

8. The colour of bacteria produced must be golden brown \& musty odour.

9. The settled sludge is used for the experiment.

\subsection{Experimental Setup}

A lab scale model of activated sludge reactor was prepared for the research. The dimensions of the aeration tank are $0.45 \times 0.23 \times 0.30$ meters in length, width and height respectively where the total volumetric capacity of the tank is 31.05 liters. The strip of $0.30 \mathrm{~m}$ length is kept diagonally at the bottom of the aeration tank having perforations closed at both ends. The strip is fixed firmly on the bottom of the tank. The aeration was done with aerator with constant and continuous supply of air.

\subsection{Experimental Procedure}

\subsubsection{Sample Collection}

Fresh dairy effluent sample was obtained from the Katraj Dairy at Pune in Maharashtra. The sample was collected in a $5 \mathrm{~L}$ plastic container. The container used for sample collection was rinsed for three times with distilled water. It was dried in an oven for 1 hour at $30^{\circ} \mathrm{C}$ and allowed to cool to room temperature. At the collection point, container was rinsed with the sample thrice and then filled, corked tightly and taken to the laboratory. It was stored at a temperature below $4^{0} \mathrm{C}$ to avoid any physico-chemical changes in the effluent.

\subsubsection{Experimentation}

The study is to be conducted by following two methods: 1) Utilizing non pre-aerated sludge 2) Utilizing pre-aerated sludge.

In the first method the dairy wastewater measuring five liters and $400 \mathrm{ml}$ of non-pre-aerated sludge is filled in the aeration tank and is to be aerated in the aeration tank where air (or oxygen) is supplied for regular intervals of 30, 60, 90, 120 minutes respectively and samples are collected before aeration and at regular intervals.

In the second method the dairy wastewater measuring five liters and $400 \mathrm{ml}$ of pre-aerated sludge (with 20, 40 and 60 minutes pre- aeration) were filled in the aeration tanks. These tanks were aerated for regular time intervals of 30 , $60,90,120$ minutes respectively and samples are collected before aeration and at regular intervals.

\subsection{Laboratory Analysis}

Testing of different parameters like Biochemical oxygen demand (BOD), Chemical Oxygen Demand (COD), Phosphate, Nitrate and Mixed liquor volatile suspended solids are to be carried out on the samples aerated with different aeration time, with and without pre-aerated sludge and consequent results are to be found. Sample names are given accordingly. 
\# Tank 1 contains non pre-aerated sludge and wastewater, \# tank 2 contains pre-aerated sludge ( $20 \mathrm{~min}$ ) and wastewater, \# tank 3 contains pre-aerated sludge $(40 \mathrm{~min})$ and wastewater and \# tank 4 contains pre-aerated sludge (60 min) and wastewater.

\section{RESULTS AND DISCUSSIONS}

The concentrations of various parameters such as BOD, COD, Phosphate, Nitrate, and MLVSS by utilization of nonpre-aerated sludge and by utilization of pre-aerated sludge in ASP are tabulated as below.

Table 1: Concentration of various parameters

\begin{tabular}{|c|c|c|c|c|c|c|}
\hline Sr.No. & Sample Name & BOD5(mg/lit) & COD(mg/lit) & Phosphate(mg/lit) & Nitrate(mg/lit) & Mlvss(mg/lit) \\
\hline 1. & Tank 1 Inlet & 1318 & 2130 & 0.648 & 0.288 & 3480 \\
\hline i) & Tank 1/1 ( $30 \mathrm{~min})$ & 1290 & 2100 & 0.638 & 0.170 & 3600 \\
\hline ii) & Tank $1 / 2(60 \mathrm{~min})$ & 1280 & 2080 & 0.639 & 0.169 & 3600 \\
\hline iii) & Tank 1/3 (90 min) & 1279 & 2075 & 0.630 & 0.269 & 3610 \\
\hline iv) & Tank 1/4 (120 min) & 1275 & 2070 & 0.630 & 0.258 & 3620 \\
\hline 2. & Tank 2 Inlet & 1300 & 2140 & 0.640 & 0.281 & 3500 \\
\hline i) & Tank $2 / 1(30 \mathrm{~min})$ & 1289 & 2100 & 0.642 & 0.242 & 3580 \\
\hline ii) & Tank 2/2 (60 min) & 1278 & 2078 & 0.630 & 0.179 & 3600 \\
\hline iii) & Tank 2/3 $(90 \min )$ & 1274 & 2069 & 0.628 & 0.178 & 3620 \\
\hline iv) & Tank 2/4 (120min) & 1270 & 2065 & 0.628 & 0.172 & 3628 \\
\hline 3. & Tank 3 Inlet & 1320 & 2180 & 0.681 & 0.182 & 3520 \\
\hline i) & Tank 3/1 ( $30 \mathrm{~min})$ & 1280 & 2140 & 0.673 & 0.144 & 3525 \\
\hline ii) & Tank 3/2 ( $60 \mathrm{~min})$ & 1272 & 2130 & 0.670 & 0.142 & 3530 \\
\hline iii) & Tank 3/3 ( $90 \mathrm{~min})$ & 1265 & 2120 & 0.671 & 0.142 & 3532 \\
\hline iv) & Tank 3/4 (120min) & 1260 & 2120 & 0.668 & 0.140 & 3534 \\
\hline 4. & Tank 4 Inlet & 1330 & 2190 & 0.672 & 0.190 & 3540 \\
\hline i) & Tank 4/1 ( $30 \mathrm{~min})$ & 1310 & 2182 & 0.672 & 0.148 & 3542 \\
\hline ii) & Tank 4/2 (60 min $)$ & 1308 & 2179 & 0.671 & 0.144 & 3546 \\
\hline iii) & Tank 4/3 (90 min) & 1300 & 2170 & 0.670 & 0.142 & 3548 \\
\hline iv) & Tank 4/4 (120 min) & 1280 & 2162 & 0.662 & 0.142 & 3550 \\
\hline
\end{tabular}

\subsection{Comparison of Removal of Different Pollutants}

From tabulated results for various samples, we can see that the concentration of BOD, COD, Phosphate, and Nitrate varies with the aeration time 30, 60, 90, 120 minutes respectively. By increasing the aeration time from $30 \mathrm{~min}$ to $120 \mathrm{~min}$, it was observed that these pollutant content levels decrease effectively by utilization of non pre-areated sludge.

In case of with pre-aerated sludge, it is seen that the BOD, COD, Phosphate, Nitrate content levels further decreases with the increase in the aeration time. It is observed that the efficiency of pollutant removal was higher when pre-aerated sludge is utilized as a medium into the conventional activated sludge process. But this is effective up to optimum duration of pre-aeration.

Since there was an increase in the growth rate of microorganisms, it leads to the increase in the consumption rate which consequently led to the decrease of content levels respectively. It was effective up to optimum duration of preaeration.

\subsection{Optimum duration for Pre aeration for Various}

\section{Samples.}

Optimum duration for pre aeration is the duration up to which removal of pollutants BOD, COD, Phosphate, Nitrate, MLVSS are effective but beyond this duration if pre aeration is done removal efficiency of pollutants decreases. The graphs can be plotted for pollutants removal verses preaeration time for 30 minutes, 60 minutes, 90 minutes and 120 minutes of aeration. From the graphs shown, we can understand about optimum duration of pre-aeration. For utilizing pre-aerated sludge in activated sludge process 20 minutes of pre-aeration is optimum pre-aeration duration for effective removal of pollutants.

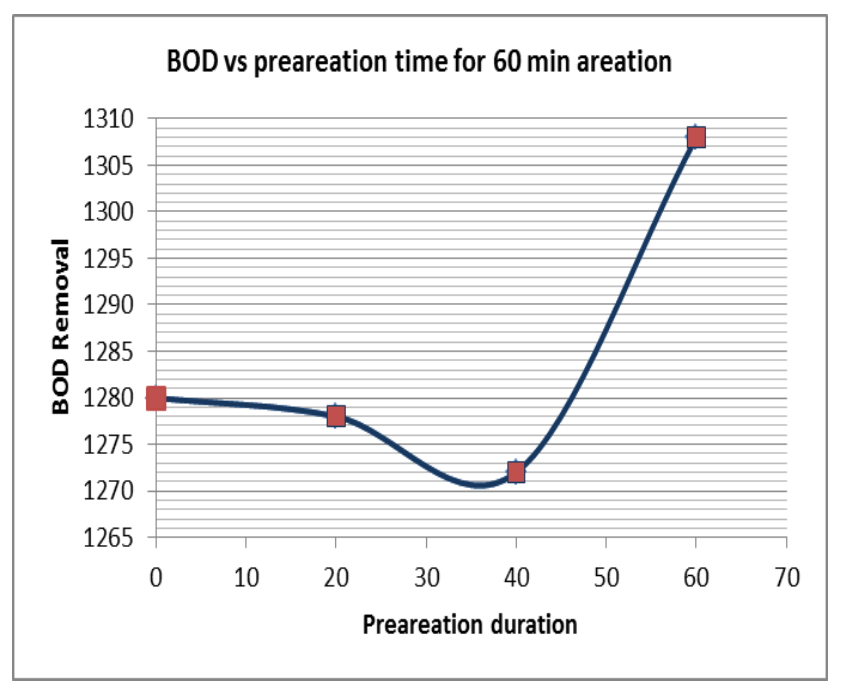

Graph 1 Optimum duration of Pre-aeration for BOD Removal 


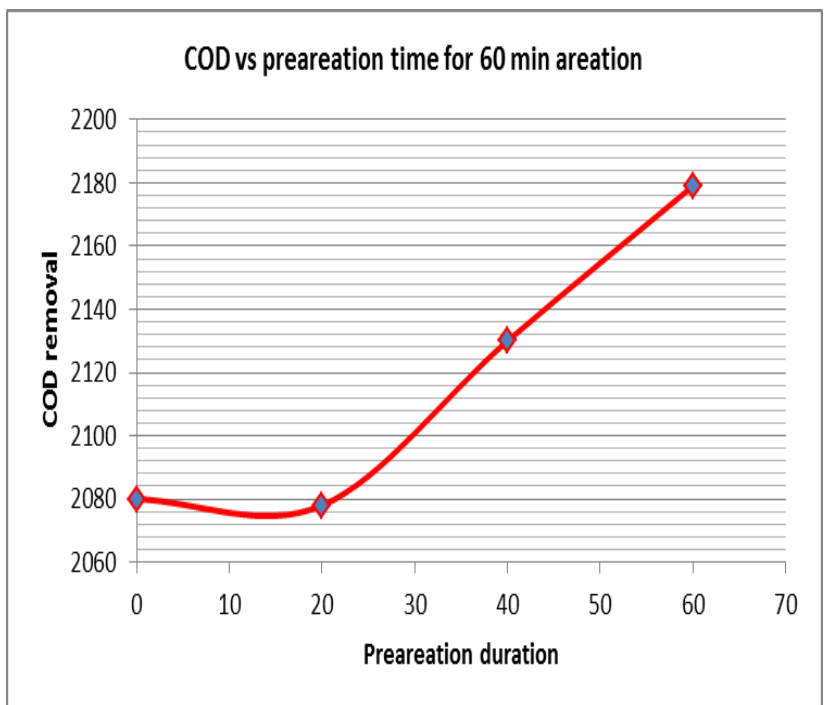

Graph 2 Optimum duration of Pre-aeration for COD Removal

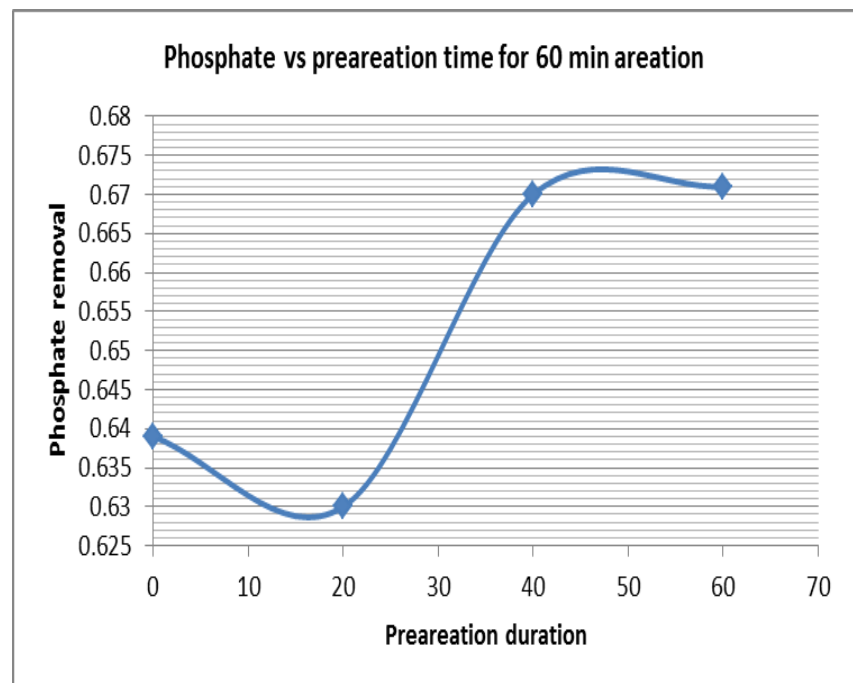

Graph 3 Optimum duration of Pre-aeration for Phosphate Removal

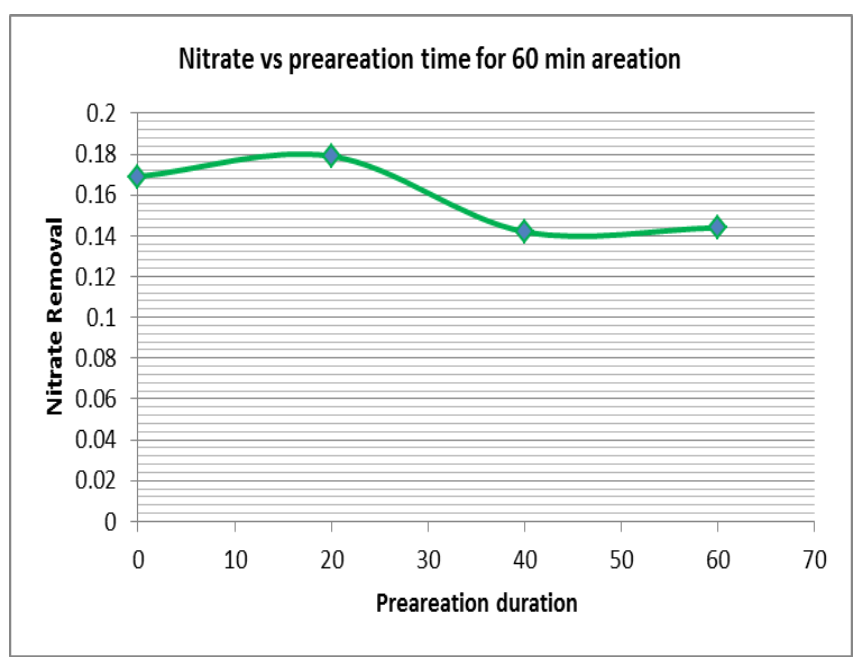

Graph 4 Optimum duration of Pre-aeration for Nitrate Removal

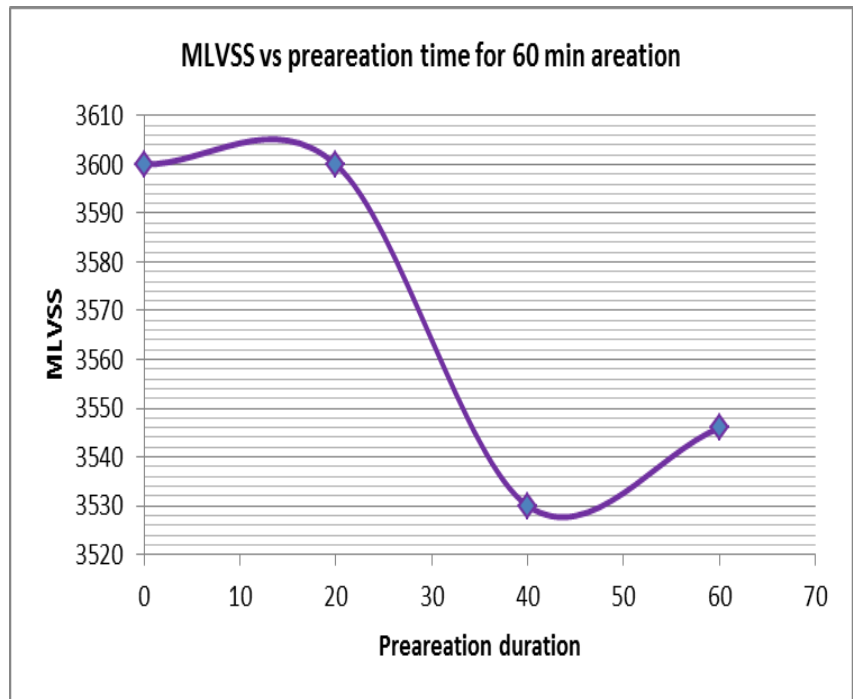

Graph 5 Optimum duration of Pre-aeration for MLVSS

\subsection{Inter-Relationship between Various Parameters}

The graphs can be plotted between various parameters BOD verses COD, BOD verses Phosphate, BOD verses Nitrate, BOD verses MLVSS Linear relationship can be obtained. The equations can be obtained with regression coefficients nearly equal to or more than 0.80 .

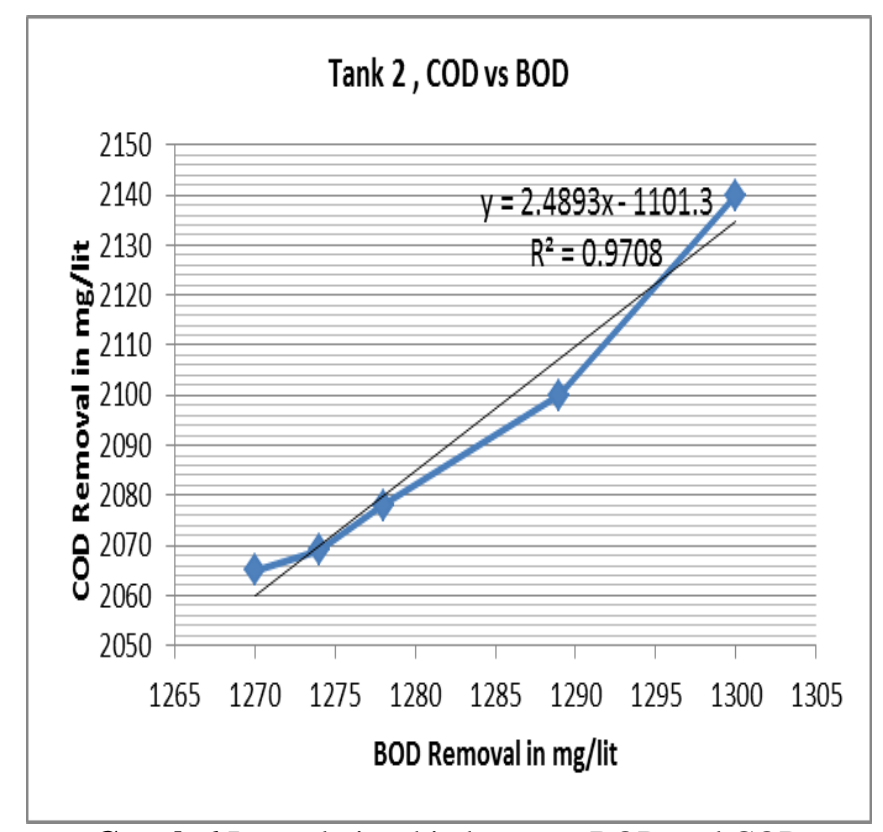

Graph 6 Interrelationship between BOD and COD 


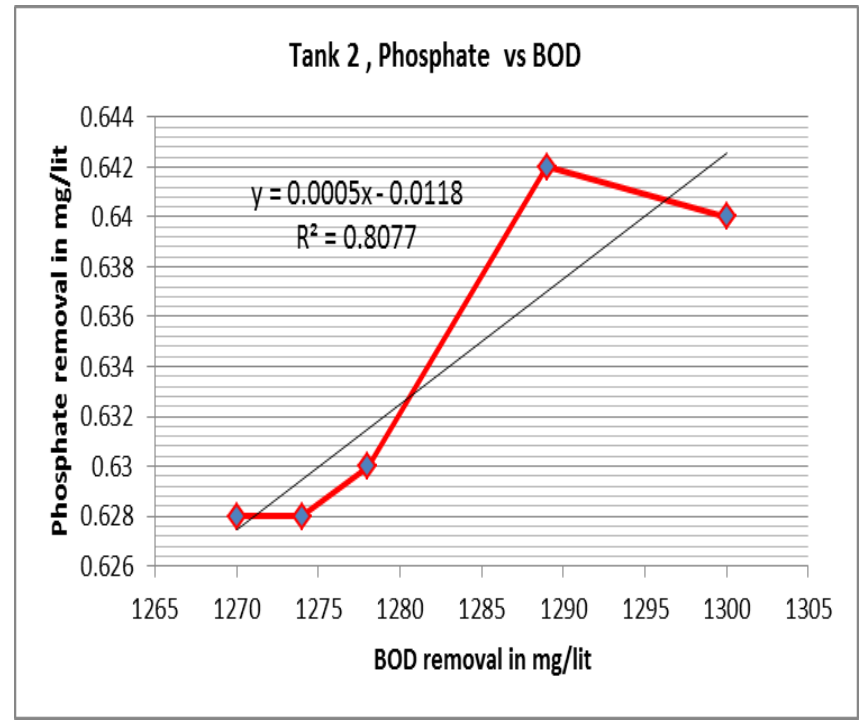

Graph 7 Interrelationship between BOD and Phosphate

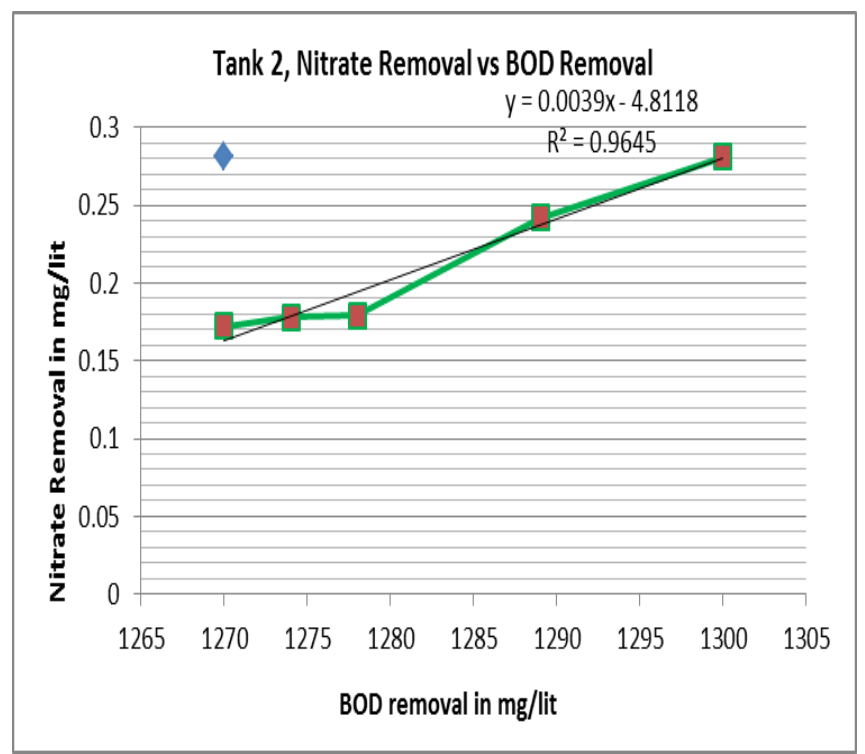

Graph 8 Interrelationship between BOD and Nitrate

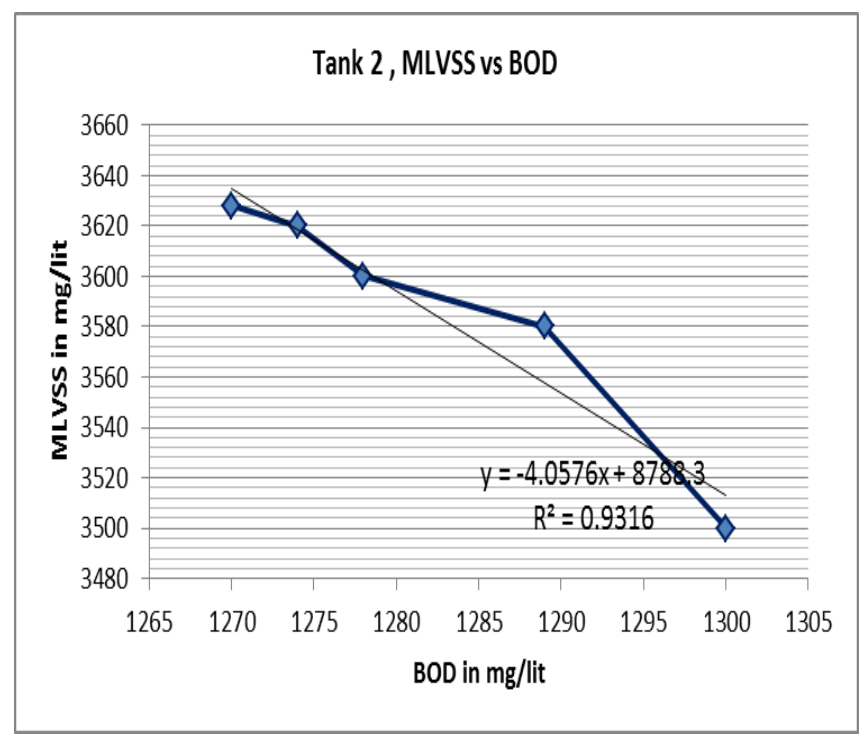

Graph 9 Interrelationship between BOD and MLVSS

\subsection{Generalized Equation between BOD and COD}

For all the tanks the equations between BOD and COD can be obtained by plotting the graphs between BOD verses COD. On $\mathrm{X}$ axis BOD values are plotted and on $\mathrm{Y}$ axis COD values can be plotted. Regression coefficients can also be obtained from these graphs. Mathematically also regression coefficients can be calculated. Difference between regression coefficients by graphs and by mathematics can be added in the equations obtained from graphs. The average of all four equation is taken and generalized equation between BOD and COD can be obtained, which is given as follows.

$$
Y=1.3763 X+1418.0734 \text {. }
$$

\section{CONCLUSION}

1) From this research work, it is observed that by using activated sludge process, the concentration of BOD, COD, Phosphate, Nitrate and MLVSS from dairy effluent has been found to be decreased by increasing the aeration time from 30 minutes to 120 minutes.

2) Further it can be enhanced by utilization of pre -aerated sludge which has increased the removal efficiency of pollutants up to optimum duration of pre aeration.

3 ) Beyond this optimum duration of pre-aeration removal of all these pollutants decreases.

4) The interrelation between BOD removal and COD removal is given by equation $\mathrm{Y}=\mathbf{1 . 3 7 6 3} \mathrm{X}+\mathbf{1 4 1 8 . 0 7 3 4}$.

\section{REFERENCES}

[1] Wastewater Treatment, Concepts and Design Approach by G.L. Karia and R.A. Christian, Second Edition , June 2013.

[2] Wastewater Engineering, Treatment and Reuse , Fourth Edition, Metcalf \& Eddy, Inc ,Tata McGraw Hill Education Private Limited.

[3] S. Haydar, J. A. Aziz, M.S.Ahmad (July 2007) “ Biological Treatment of Tannery Wastewater Using Activated Sludge Process" in Pak. J. Engg. \& Appl.Sci.Vol.1 July 2007.

[4] Muhammad Khalid Iqbal , Tahira Shafiq, Amana Nadeem (2007) "Biological Treatment of Textile Wastewater by Activated Sludge Process." In Jour. Chem. Soc. Pak .Vol. 29, No. 5, 2007

[5] Saad A. Al-Jlil (2009) " COD and BOD Reduction of Domestic Wastewater using Activated Sludge, Sand Filters and Activated Carbon in Saudi Arabia."

[6] Saritha. B, Veda .M, Silari Venkatesh (May 2011 ) "Study of Activated Sludge Process using Medium in Treatment of Wastewater " in International Journal of Engineering Trends and Technology ( IJETT) - Volume 1, Issue 2 - May 2011.

[7] Ambreen Lateef , Muhammad Nawaz Chaudhry, Shazia Ilyas ( in 2013) "Biological Treatment of Dairy Wastewater using activated sludge." Science Asia 39 (2013): 179-185 